\title{
A force field for secondary chlorides
}

\author{
C. G. OpaskaR* and S. KRIMM \\ Harrison M. Randall Laboratory of Physics, University of Michigan, Ann Arbor \\ Michigan
}

(Received 22 December 1966)

\begin{abstract}
A force field has been derived for monochloro- and 2,4-dichloro-hydrocarbons. The Snyder-Schachtschneider force field for hydrocarbons was used as a starting point, the constants associated with the secondary chlorine being determined from an assignment of the gas phase spectrum of 2-chloropropane and the carbon-chlorine stretching frequencies of the three isomers of 2-chlorobutane. The force field was tested on 3-chloropentane, axial and equatorial monochlorocyclohexane, and the most stable conformations of $d l$ and meso 2,4-dichloropentane, giving good agreement in all of these cases. The conformation dependence of the carbonchlorine stretching frequency is thus shown to derive primarily from structural differences between conformers.
\end{abstract}

\section{INTRODUCTION}

THE experimental correlation of vibrational frequencies with rotational isomeric structure in secondary chlorides is now well established $[1,2]$. In particular, a detailed study of model compounds [2] has shown that the absorption bands arising from the stretching of the carbon-chlorine bond have frequencies which are sensitive both to the two atoms trans to the chlorine atom across the neighboring carboncarbon bonds as well as to the local conformation of the carbon chain. This dependence is summarized in Fig. 1, which shows the six conformations possible near a chlorine atom and the observed carbon-chlorine stretching frequencies associated with each. The conformations are labelled $S$ (for secondary chlorine), with subscripts designating the atoms trans to the chlorine and primes to distinguish conformations in which, for trans hydrogens, the next-nearest-neighbor carbon atoms have been rotated away from the planar zig-zag position [2]. These rotations about carboncarbon bonds are taken to have values of $+120^{\circ}$ and $-120^{\circ}$ from the trans planar zig-zag conformation, an assumption which may not be exactly correct in all cases since non-bonded interactions in linear molecules may lead to stabilization of structures with slightly different values of this torsion angle [3]. The correlation ranges for $S_{\mathrm{HH}}, S_{\mathrm{HH}^{\prime}}$, and $S_{\mathrm{CH}}$ are derived from a detailed study of model compounds in which, in some instances, the conformational structure is unambiguous [2]. The $S_{\mathrm{H}^{\prime} \mathrm{H}^{\prime}}$ frequency correlation is obtained from the spectrum of the unique structure of axial monochlorocyclohexane [4], interpreted in terms of our calculations (see below). The $S_{\mathrm{CO}}$ frequencies are those observed for 2,2,4,4-tetramethyl-3-chloropentane, $758 \mathrm{~cm}^{-1}$ [2], and for equatorial monochlorocyclohexane, $728 \mathrm{~cm}^{-1}$ [4], both molecules being cases in which the conformation is unambiguously determinable.

* Present address: Shell Development Co., Houston, Texas.

[1] S. Mizushima, T. Shimanodchi, K. Nakamura, M. Hayashi and S. Tsuohiya, J. Chem. Phys. 26, 970 (1957).

[2] J. J. Shipman, V. L. Folt and S. Krimm, Spectrochim. Acta 18, 1603 (1962).

[3] R. A. ScotT and H. A. ScheragA, J. Chem. Phys. 44, 3054 (1966).

[4] P. Krafboe, J. J. Lothe and K. LuNDe, Acta Chem. Scand. 10, 1465 (1956). 
No comparable molecule has been found for the $S_{\mathrm{CH}}$, conformation, so that the carbon-chlorine stretching frequency for this structure is as yet not known with certainity, although it has been claimed to be located at $667 \mathrm{~cm}^{-1}$ in 3-chloropentane [5].

The origin of this dependence of carbon-chlorine stretching frequency on conformation has not as yet been elucidated in any detail. It could arise from either of two essentially different factors: the dependence of frequency on structural differences between conformations, or the dependence on potential energy terms
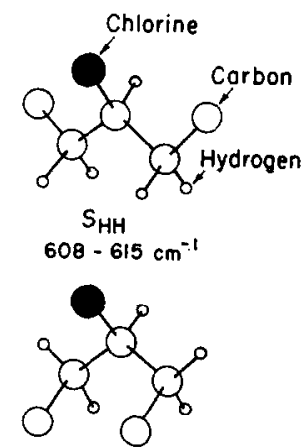

$$
\mathrm{S}_{\mathrm{H}^{\prime} \mathrm{H}^{\prime}}
$$

$557 \mathrm{~cm}^{-1}$ and $683 \mathrm{~cm}^{-1}$
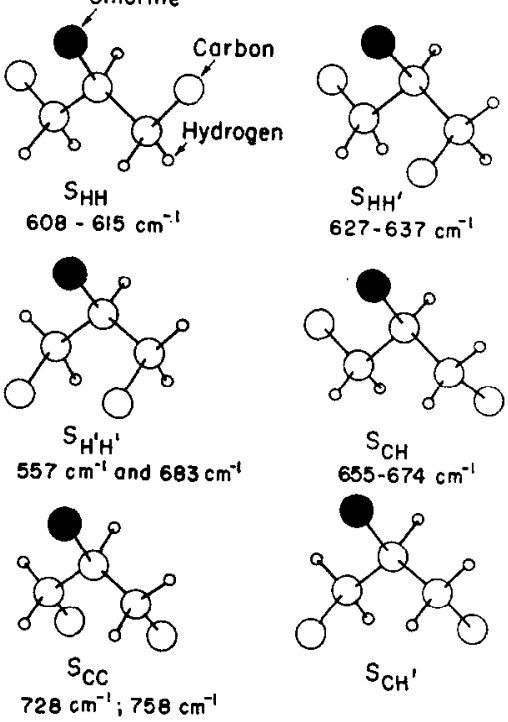

Fig. 1. Conformations of secondary chlorides and empirically determined carbon-chlorine stretching frequencies.

which are specific to each conformation. Or it might result from a combination of these factors. We have examined the first of these possibilities, attempting to derive a force field which contains no dominant conformation-dependent potential energy terms. It appears that this is possible to a good approximation for monochloroand 2,4-dichloro-hydrocarbons, which are the systems which we have investigated.

\section{Derivation of the Force Field}

Our approach to the derivation of a force field for secondary chlorides was the following. A very satisfactory valence force field has been determined for saturated hydrocarbons [6], based on the refinement of 308 observed frequencies in 17 molecules. The force constants in this potential function were transferred, where applicable, to the chlorinated hydrocarbons, some minor interaction constants being dropped. Another set of force constants for primary chlorides was available [7], which required only a few additional constants to make it suitablo for secondary chlorides. This

[5] A. Caraculaco, J. Štokr and B. Schnerder, Coll. Czech. Chem. Commun. 29, 2783 (1964).

[6] R. G. SNYDER and J. H. SOHACHTSOHNHIDFr, Spectrochim. Acta 21, 169 (1965).

[7] J. H. SOHACHTSCHNEIDER, private communication. 
combined set of force constants was used to fitall of the frequencies of 2-chloropropane and the carbon-chlorine stretching frequencies of the three conformations of 2chlorobutane, adjustments being made only in some of the chlorine constants. The force field was then tested on various monochloro- and dichloro-hydrocarbons to determine if it was transferable and therefore acceptable as a satisfactory potential function for secondary chlorides. Torsion coordinates were not included in these calculations primarily because no experimental data are available on such frequencies in secondary chlorides. A model calculation using a torsion constant which gave calculated torsion frequencies of about $200 \mathrm{~cm}^{-1}$, approximately the value in propane

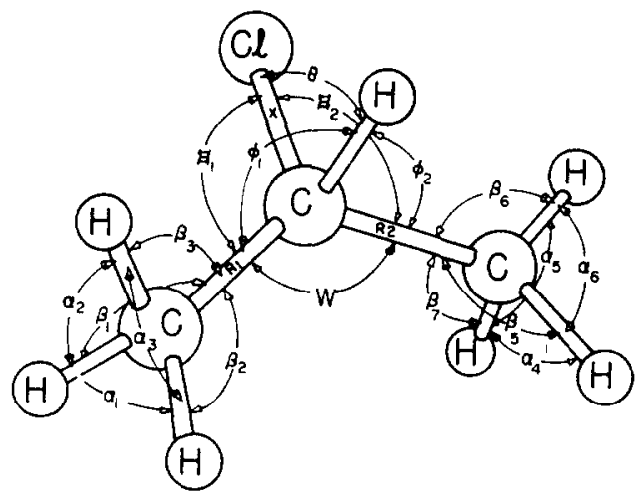

Fig. 2. Molecule of 2-chloropropane with internal coordinates.

[8], showed that the torsion coordinates interact only very weakly with the carbonchlorine stretching coordinate: the carbon-chlorine stretching frequency is shifted by only $2 \mathrm{~cm}^{-1}$. We felt, therefore, that the conclusions concerning the conformation dependence of the carbon-chlorine stretching frequency would not be significantly affected by the exclusion of torsion angles.

\section{Assignments for 2-chloropropane}

In order to use 2-chloropropane in the refinement procedure for the force constants involving the chlorine atom, it was necessary to have correct assignments for the vibrational bands. This was done by comparison of the spectrum with that of propane, and by study of the gas phase band contours.

The molecule of 2-chloropropane is illustrated in Fig. 2. Its gas phase spectrum is shown in Fig. 3. The shape of an absorption band in the gas phase spectrum of an asymmetric top molecule depends upon the orientation of the corresponding vibrational dipole moment with respect to the axes of the principal moments of inertia of the molecule [9]. If the changing dipole moment is parallel to the axis of least moment of inertia then the absorption band will have a strong central maximum with two weaker maxima on either side. This is also true if the changing dipole moment is parallel to the axis of greatest moment of inertia, so long as the molecule is not close to being a symmetric top. On the other hand, if the changing dipole moment is parallel to the axis of intormodiato momont of

[8] J. H. SCHAChtschneider and R. G. SNXDER, Spectrochim. Acta 19, 117 (1963).

[9] G. HerzBerg, Infrared and Raman Spectra. Van Nostrand (1945). 
inertia the central maximum will be absent from the absorption band. The moments of inertia of 2-chloropropane were calculated using the following constants: $m_{\mathrm{H}}=1 \mathrm{amu}, m_{\mathrm{C}}=12 \mathrm{amu}, m_{\mathrm{Cl}}=35 \mathrm{amu}, r(\mathrm{CH})=1.09 \AA, r(\mathrm{CC})=1.54 \AA, r(\mathrm{CCl})$ $=1.795 \AA$, all angles tetrahedral. They were found to be $62.33,109.3$ and 155.2 amu- $\AA^{2}$, the principal axes corresponding to the greatest and least moments of inertia being located in the symmetry plane of the molecule while the axis corresponding to the intermediate moment is perpendicular to this plane. This fortunate circumstance thus permits the band shape to be used to identify the symmetry type of the corresponding vibrational mode.

A quantitative characterization of the expected band shape is also possible by determining the separation of the outer maxima in the two band types considered

2 - CHLOROPROPANE GAS SPECTRUM

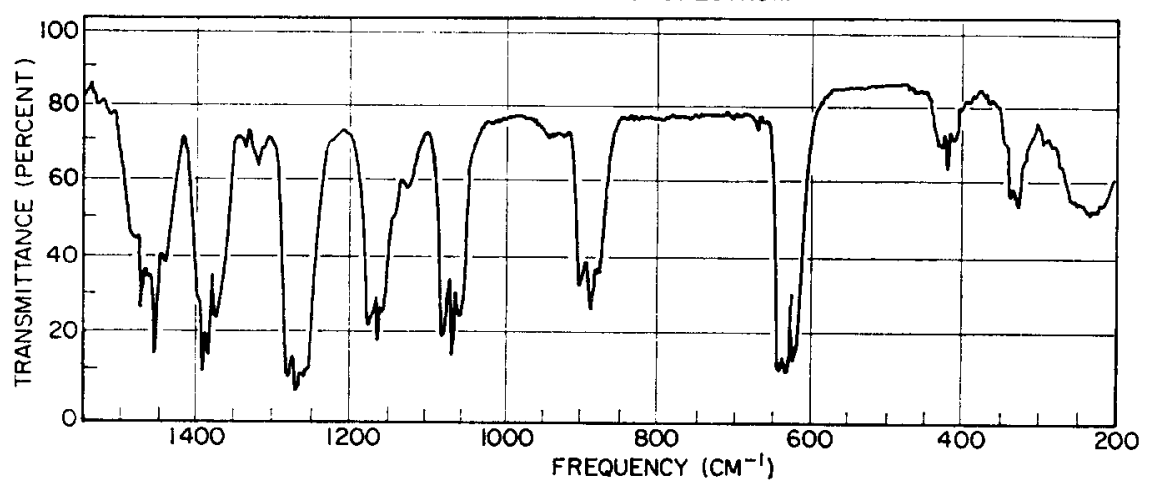

Fig. 3. Infrared spectrum of 2-chloropropane, gas phase, room temperature.

above [10]. Such calculations lead to the prediction that bands with a central maximum will have outer maxima separated by about $20 \mathrm{~cm}^{-1}$, while bands without. a central maximum will have the outer maxima separated by about $10 \mathrm{~cm}^{-1}$.

Absorption bands with the above charactcristics are indeed identifiable in the spectrum. Thus, bands in the gas phase spectrum centered at $421,630,887,1065$, 1163 , and $1269 \mathrm{~cm}^{-1}$ can be assigned unambiguously to modes which are symmetric with respect to the symmetry plane (the plane of the $\mathrm{CHCl}$ group), while bands at 930 and $1130 \mathrm{~cm}^{-1}$ can be assigned to antisymmetric modes. In several other cases band overlap occurs, but a sorting out based on the predicted separation of the maxima, as well as on the location of the liquid phase peaks (see Table 3), seems feasible. Thus, in the low frequency region the observed band contour can be accounted for by a symmetric band centered at $335 \mathrm{~cm}^{-1}$ plus an antisymmetric band centered at $324 \mathrm{~cm}^{-1}$. The group of bands near $1325 \mathrm{~cm}^{-1}$ is best fitted by a symmetric band centered near $1315 \mathrm{~cm}^{-1}$ and an antisymmetric band centered at $1330 \mathrm{~cm}^{-1}$. The band contour near $1375 \mathrm{~cm}^{-1}$ is very satisfactorily accounted for by a symmetric band centered at $1392 \mathrm{~cm}^{-1}$ and an antisymmetric band centered at $1378 \mathrm{~cm}^{-1}$.

The general nature of the mode associated with a given band is determinable on

[10] R. M. Badger and L. R. Zumwalt, J. Chem. Phys, 6, 711 (1938). 
the basis of the assignments for propane [8]. Thus the 2-chloropropane band at $421 \mathrm{~cm}^{-1}$ can be correlated with the CCC bending mode of propane observed at $375 \mathrm{~cm}^{-1}$. The $630 \mathrm{~cm}^{-1}$ band is obviously the carbon-chlorine stretching mode [2]. The symmetric CC stretching mode occurs in propane at $868 \mathrm{~cm}^{-1}$, and the $887 \mathrm{~cm}^{-1}$ band of 2-chloropropane is therefore most reasonably associated with this vibration. In propane a band at $921 \mathrm{~cm}^{-1}$ is assigned to the antisymmetric $\mathrm{CCH}$ bending mode of the two methyl groups; a comparable assignment to the antisymmetric band in 2-chloropropane at $930 \mathrm{~cm}^{-1}$ is indicated. The totally symmetric methyl $\mathrm{CCH}$ bending mode in propane is located at $1157 \mathrm{~cm}^{-1}$, which suggests such an assignment for the $1163 \mathrm{~cm}^{-1}$ band of 2-chloropropane. Two major modes for which the frequency correspondence is not so close are: (a) the $B_{2}$ methyl CCH bending vibration of propane at $1187 \mathrm{~cm}^{-1}$, which would be a symmetric vibration in 2-chloropropane, and (b) the $B_{1}$ antisymmetric CC stretching mode of propane at $1052 \mathrm{~cm}^{-1}$, which would also be antisymmetric in 2-chloropropane. On the basis of band symmetrics we assign these modes to the 2 -chloropropane bands at 1065 and $1130 \mathrm{~cm}^{-1}$ respectively. The very large difference in frequency in the first case may not be unexpected, since in propane this vibration has a large contribution from $\mathrm{CH}_{2}$ rocking [8], which disappears in 2-chloropropane. A similar disparity in contributions from various internal coordinates could account for the difference in the antisymmetric CC stretching frequencies (see Table 3). The internal symmetric methyl bending modes of propane at $1389 \mathrm{~cm}^{-1}\left(A_{1}\right)$ and $1370 \mathrm{~cm}^{-1}\left(B_{1}\right)$ have their counterparts (with appropriate symmetry) in the 2-chloropropane bands at 1392 and $1378 \mathrm{~cm}^{-1}$ respectively. The assignment of the strong symmetric band of 2-chloropropane at $1269 \mathrm{~cm}^{-1}$ to a movement of the $\mathrm{H}$ atom of the $\mathrm{CHCl}$ group in the symmetry plane is now indicated, as is the assignment of the $1330 \mathrm{~cm}^{-1}$ band to the motion of this $\mathrm{H}$ atom perpendicular to the symmetry plane (the analogous $\mathrm{CH}_{2}$ wagging mode of propane occurs at $1331 \mathrm{~cm}^{-1}$ ).

Since the hydrocarbon portion of our potential function was transferred without modification from the earlier work [6], we expect the corresponding calculated normal modes of 2-chloropropane to fit in with the assignments arrived at above from the experimental data. As we shall see this is indeed the case. The assignments of the remaining bands to motions within the carbon-chlorine portion of the molecule should then provide guidelines for refining those additional force constants associated with this group.

\section{Assignments for 2-chlorobutane}

Since 2-chlorobutane exists as a mixture of three conformational isomers, $S_{\mathrm{HH}}, S_{\mathrm{HH}}$, and $S_{\mathrm{CH}}$ [2], an analysis of its spectrum comparable to that done above for 2-chloropropane was not feasible. However, the three carbon-chlorine stretching vibrations are convincingly known [2], and could be used in the refinement procedure. They are, for the liquid: $S_{\mathrm{HH}^{-}} 607 \mathrm{~cm}^{-1}, S_{\mathrm{HH}^{\prime}}-627 \mathrm{~cm}^{-1}, S_{\mathrm{CH}^{-}}-670 \mathrm{~cm}^{-1}$. It might be remarked here that these frequencies vary somewhat with the phase of the specimen, probably mainly as a result of differential environmental effects, although in some cases possibly due to small changes in internal geometry. We have chosen the liquid state frequencies as our standard ones, primarily because most molecules were studied in this state. 


\section{Refinement of the force field}

The force field was determined through normal coordinate calculations on 2chloropropane and 2-chlorobutane combined with a study of possibly pertinent elements of the Jacobian matrix. This is a matrix whose elements are the derivatives of the frequencies with respect to the force constants [11]. Using the elements of

Table 1. Force constants for secondary chlorides

\begin{tabular}{|c|c|c|c|c|}
\hline Name & Value & Environment & \multicolumn{2}{|l|}{ Coordinates coupled } \\
\hline$K_{r}$ & 4.699 & $\mathrm{C}\left(\mathrm{H}_{1}, \mathrm{H}_{2}, \mathrm{H}_{\mathbf{3}}\right)$ & $\left(\mathrm{C}, \mathrm{H}_{1}\right)$ & \\
\hline$F_{r}$ & 0.043 & $\mathrm{C}\left(\mathrm{H}_{1}, \mathrm{H}_{2}, \mathrm{H}_{3}\right)$ & $\left(\mathrm{C}, \mathrm{H}_{1}\right)\left(\mathrm{C}, \mathrm{H}_{2}\right)$ & \\
\hline$K_{d}$ & 4.554 & $\mathrm{C}_{1}-\mathrm{C}_{2}\left(\mathrm{H}_{1}\right)-\mathrm{C}_{3}$ & $\left(\mathrm{C}_{2}, \mathrm{H}_{1}\right)$ & \\
\hline$F_{d}$ & 0.006 & $\mathrm{C}_{1}-\mathrm{C}_{2}\left(\mathrm{H}_{1}, \mathrm{H}_{\mathrm{z}}\right)-\mathrm{C}_{\mathrm{z}}$ & $\left(\mathrm{C}_{y}, \mathrm{H}_{1}\right)\left(\mathrm{C}_{2}, \mathrm{H}_{\mathrm{z}}\right)$ & \\
\hline$K_{R}$ & 4.387 & $\mathrm{C}_{\mathrm{x}}-\mathrm{C}_{2}$ & $\left(C_{1}, C_{2}\right)$ & \\
\hline$F_{R}$ & 0.101 & $\mathrm{C}_{1}-\mathrm{C}_{3}-\mathrm{C}_{3}$ & $\left(\mathrm{C}_{1}, \mathrm{C}_{2}\right)\left(\mathrm{C}_{2}, \mathrm{C}_{2}\right)$ & \\
\hline$F_{R \gamma}$ & 0.328 & $\mathrm{C}_{1}-\mathrm{C}_{2}(\mathrm{H})$ & $\left(\mathrm{C}_{1}, \mathrm{C}_{2}\right)\left(\mathrm{C}_{1}, \mathrm{C}_{2}, \mathrm{H}\right)$ & \\
\hline$F_{R \gamma^{\prime}}$ & 0.079 & $\mathrm{C}_{1}-\mathrm{C}_{2}(\mathrm{H})-\mathrm{C}_{3}$ & $\left(\mathrm{C}_{1}, \mathrm{C}_{2}\right)\left(\mathrm{H}, \mathrm{C}_{2}, \mathrm{C}_{2}\right)$ & \\
\hline$F_{R Q}$ & 0.417 & $\mathrm{C}_{1}-\mathrm{C}_{2}-\mathrm{C}_{8}$ & $\left(C_{2}, C_{2}\right)\left(C_{1}, C_{2}, C_{3}\right)$ & \\
\hline$H_{\alpha}$ & 0.540 & $\mathrm{C}\left(\mathrm{H}_{1}, \mathrm{H}_{\mathbf{2}}, \mathrm{H}_{\mathbf{2}}\right)$ & $\left(\mathrm{H}_{1}, \mathrm{C}, \mathrm{H}_{2}\right)$ & \\
\hline$H^{0}$ & 0.550 & $\mathrm{C}_{1}-\mathrm{C}_{2}\left(\mathrm{H}_{1}, \mathrm{H}_{2}\right)-\mathrm{C}_{2}$ & $\left(\mathrm{H}_{1}, \mathrm{C}_{2}, \mathrm{H}_{2}\right)$ & \\
\hline$H \beta$ & 0.645 & $\mathrm{C}_{1}-\mathrm{C}_{8}\left(\mathrm{H}_{1}, \mathrm{H}_{2}, \mathrm{Ir}_{2}\right)$ & $\left(\mathrm{C}_{1}, \mathrm{C}_{2}, \mathrm{H}_{1}\right)$ & \\
\hline$F \beta$ & -0.012 & $\mathrm{C}_{1}-\mathrm{C}_{2}\left(\mathrm{H}_{1}, \mathrm{H}_{2}, \mathrm{H}_{3}\right)$ & $\left(\mathrm{C}_{1}, \mathrm{C}_{2}, \mathrm{H}_{1}\right)\left(\mathrm{C}_{1}, \mathrm{C}_{2}, \mathrm{H}_{2}\right)$ & \\
\hline$H_{\gamma}$ & 0.656 & $\mathrm{C}_{2}-\mathrm{C}_{2}\left(\mathrm{H}_{1}, \mathrm{H}_{2}\right)-\mathrm{C}_{3}$ & $\left(\mathrm{C}_{1}, \mathrm{C}_{2}, \mathrm{H}_{1}\right)$ & \\
\hline$F_{\gamma}$ & -0.021 & $\mathrm{C}_{1}-\mathrm{C}_{2}\left(\mathrm{H}_{3}, \mathrm{H}_{2}\right)-\mathrm{C}_{2}$ & $\left(\mathrm{C}_{1}, \mathrm{C}_{2}, \mathrm{H}_{1}\right)\left(\mathrm{C}_{1}, \mathrm{C}_{2}, \mathrm{H}_{2}\right)$ & \\
\hline$F_{\gamma^{\prime}}$ & 0.013 & $\mathrm{C}_{1}-\mathrm{C}_{2}\left(\mathrm{H}_{1}, \mathrm{H}_{2}\right)-\mathrm{C}_{3}$ & $\left(\mathrm{C}_{1}, \mathrm{C}_{2}, \mathrm{H}_{2}\right)\left(\mathrm{H}_{1}, \mathrm{C}_{2}, \mathrm{C}_{2}\right)$ & \\
\hline$H_{\omega}$ & 1.130 & $\mathrm{C}_{2}-\mathrm{C}_{2}-\mathrm{C}_{3}$ & $\left(C_{1}, C_{2}, C_{2}\right)$ & \\
\hline$F_{\gamma \omega}$ & -0.031 & $\mathrm{C}_{2}-\mathrm{C}_{2}(\mathrm{H})-\mathrm{C}_{3}$ & $\left(C_{1}, C_{2}, C_{2}\right)\left(C_{2}, C_{2}, H\right)$ & \\
\hline$f_{\omega^{t}}^{t}$ & -0.011 & $\mathrm{C}_{2}-\mathrm{C}_{2}-\mathrm{C}_{3}-\mathrm{C}_{4}$ & $\left(\mathrm{C}_{1}, \mathrm{C}_{2}, \mathrm{C}_{2}\right)\left(\mathrm{C}_{2}, \mathrm{C}_{2}, \mathrm{C}_{\mathrm{j}}\right)$ & 180 \\
\hline$f_{\gamma \infty} t^{\prime}$ & 0.049 & $\mathrm{C}_{1}-\mathrm{C}_{2}-\mathrm{C}_{3}-\mathrm{H}$ & $\left(\mathrm{C}_{1}, \mathrm{C}_{2}, \mathrm{C}_{2}\right)\left(\mathrm{C}_{2}, \mathrm{C}_{2}, \mathrm{H}\right)$ & 180 \\
\hline$f_{\gamma \omega^{\circ}}$ & -0.052 & $\mathrm{C}_{1}-\mathrm{C}_{2}-\mathrm{C}_{8}-\mathrm{H}$ & $\left(\mathrm{C}_{1}, \mathrm{C}_{2}, \mathrm{C}_{8}\right)\left(\mathrm{C}_{2}, \mathrm{C}_{8}, \mathrm{H}\right)$ & 60 \\
\hline$f y^{t}$ & 0.127 & $\mathrm{H}_{1}-\mathrm{C}_{1}-\mathrm{C}_{2}-\mathrm{H}_{2}$ & $\left(\mathrm{H}_{1}, \mathrm{C}_{1}, \mathrm{C}_{2}\right)\left(\mathrm{C}_{1}, \mathrm{C}_{2}, \mathrm{H}_{2}\right)$ & 180 \\
\hline$f_{\gamma} \theta$ & -0.005 & $\mathrm{H}_{1}-\mathrm{C}_{1}-\mathrm{C}_{2}-\mathrm{H}_{2}$ & $\left(\mathrm{H}_{1}, \mathrm{C}_{1}, \mathrm{C}_{2}\right)\left(\mathrm{C}_{1}, \mathrm{C}_{2}, \mathrm{H}_{2}\right)$ & 60 \\
\hline${ }^{*} K_{\mathbf{x}}$ & 3.338 & $C-X(X=$ ohlorine $)$ & (C, X) & \\
\hline${ }^{*} K_{R} \mathbf{X}$ & 4.023 & $\mathrm{C}_{1}(\mathrm{H}, \mathrm{X})-\mathrm{C}_{2}$ & $\left(C_{1}, C_{2}\right)$ & \\
\hline$F_{R \mathrm{X}}$ & 0.730 & $\mathrm{C}_{2}-\mathrm{C}_{2}-\mathrm{X}$ & $\left(\mathrm{C}_{1}, \mathrm{C}_{2}\right)\left(\mathrm{C}_{2}, \mathrm{X}\right)$ & \\
\hline${ }^{*} F_{I \omega}$ & -0.220 & $\mathrm{C}_{1}-\mathrm{C}_{2}(\mathrm{X})-\mathrm{C}_{2}$ & $\left(\mathrm{C}_{2}, \mathrm{X}\right)\left(\mathrm{C}_{1}, \mathrm{C}_{2}, \mathrm{C}_{2}\right)$ & \\
\hline$f_{\gamma \omega^{x}}$ & -0.031 & $\mathrm{C}_{1}-\mathrm{C}_{8}(\mathrm{X}, \mathrm{H})-\mathrm{C}_{3}$ & $\left(\mathrm{C}_{1}, \mathrm{C}_{2}, \mathrm{C}_{3}\right)\left(\mathrm{C}_{2}, \mathrm{C}_{2}, \mathrm{H}\right)$ & \\
\hline$K_{d} X$ & 4.846 & $\mathrm{C}(\mathrm{H}, \mathrm{X})$ & (C, H) & \\
\hline$H \Xi$ & 0.982 & $\mathrm{C}_{1}-\mathrm{C}_{8}-\mathrm{X}$ & $\left(C_{1}, C_{2}, X\right)$ & \\
\hline $\bar{F} \Xi$ & 0.075 & $\mathrm{C}_{1}-\mathrm{C}_{2}-\mathrm{X}$ & $\left(\mathrm{C}_{1}, \mathrm{C}_{2}\right)\left(\mathrm{C}_{1}, \mathrm{C}_{2}, \mathrm{X}\right)$ & \\
\hline${ }^{*} F_{B} \bar{x}$ & 0.300 & $\mathrm{C}_{2}-\mathrm{C}_{2}(\mathrm{X})-\mathrm{C}_{3}$ & $\left(C_{1}, C_{2}\right)\left(C_{2}, C_{2}\right)$ & \\
\hline$F \times \Xi$ & 0.550 & $\mathrm{C}_{1}-\mathrm{C}_{2}-\mathrm{X}$ & $\left(\mathrm{C}_{2}, \mathrm{X}\right)\left(\mathrm{C}_{1}, \mathrm{C}_{2}, \mathrm{X}\right)$ & \\
\hline$H_{\theta}$ & 0.860 & $\mathrm{C}(\mathrm{X}, \mathrm{H})$ & $(\mathrm{X}, \mathrm{C}, \mathrm{H})$ & \\
\hline${ }^{*} H_{\phi}$ & 0.633 & $\mathrm{C}_{1}-\mathrm{C}_{2}(\mathrm{H}, \mathrm{X})$ & $\left(\mathrm{C}_{1}, \mathrm{C}_{2}, \mathrm{H}\right)$ & \\
\hline$F_{\gamma \theta}$ & 0.089 & $\mathrm{C}_{1}-\mathrm{C}_{2}(\mathrm{H}, \mathrm{X})$ & $\left(\mathrm{C}_{1}, \mathrm{C}_{2}, \mathrm{H}\right)\left(\mathrm{H}, \mathrm{C}_{2}, \mathrm{X}\right)$ & \\
\hline$F_{\mathbf{X} \theta}$ & 0.333 & $\mathrm{C}(\mathrm{H}, \mathrm{X})$ & $(\mathrm{C}, \mathrm{X})(\mathbf{H}, \mathrm{C}, \mathrm{X})$ & \\
\hline$f_{\gamma} \Xi^{g}$ & -0.037 & $\mathrm{C}_{1}(\mathrm{H})-\mathrm{C}_{2}(\mathrm{X})$ & $\left(\mathrm{H}, \mathrm{C}_{1}, \mathrm{C}_{2}\right)\left(\mathrm{C}_{1}, \mathrm{C}_{2}, \mathrm{X}\right)$ & 60 \\
\hline$f_{y} \Xi^{t}$ & 0.070 & $\mathrm{C}_{1}(\mathrm{H})-\mathrm{C}_{2}(\mathbf{X})$ & $\left(\mathrm{H}, \mathrm{C}_{1}, \mathrm{C},\left(\mathrm{C}_{1}, \mathrm{C}_{2}, \mathrm{X}\right)\right.$ & 180 \\
\hline$f_{\omega} \Xi^{t}$ & 0.041 & $\mathrm{C}_{1}-\mathrm{C}_{2}-\mathrm{C}_{3}(\mathrm{X})$ & $\left(\mathrm{C}_{1}, \mathrm{C}_{2}, \mathrm{C}_{8}\right)\left(\mathrm{C}_{2}, \mathrm{C}_{2}, \mathrm{X}\right)$ & 180 \\
\hline$f_{\omega} \Xi^{g}$ & -0.024 & $\mathrm{C}_{1}-\mathrm{C}_{2}-\mathrm{C}_{3}(\mathrm{X})$ & $\left(\mathrm{C}_{1}, \mathrm{C}_{2}, \mathrm{C}_{8}\right)\left(\mathrm{C}_{2}, \mathrm{C}_{3}, \mathrm{X}\right)$ & 60 \\
\hline
\end{tabular}

* Modified or added force constant.

Bond stretching constants in mdyn/A.

Angle bending constants in mdyn $A$.

the Jacobian as a guide, five force constants were either added or modified in the set based on the hydrocarbon [6] and primary chloride [7] constants. These modifications, although implying a choice of force field, were straightforward enough so that use of a least squares procedure did not seem warranted.

[11] D. A. Long, R. B. Gravenor and M. Woodger, Spectrochim. Acta 19, 937 (1963). 
The final set of force constants is shown in Table 1. The notation is explained by the following examples:

(1) CH stretching constant for a primary carbon $-K_{r}$

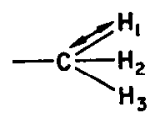

Environment: $\mathrm{C}\left(\mathrm{H}_{1}, \mathrm{H}_{2}, \mathrm{H}_{3}\right)$; Coordinates coupled: $\left(\mathrm{C}, \mathrm{H}_{1}\right)$

(2) Interaction between two $\mathrm{CCH}$ angles for $\mathrm{H}$ atoms in the trans position- $f_{\gamma}{ }^{*}$

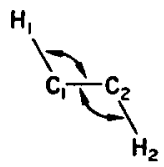

Environment: $\mathrm{H}_{1}-\mathrm{C}_{1}-\mathrm{C}_{2}-\mathrm{H}_{2}$; Coordinates coupled: $\left(\mathrm{H}_{1}, \mathrm{C}_{1}, \mathrm{C}_{2}\right)\left(\mathrm{C}_{1}, \mathrm{C}_{2}, \mathrm{H}_{2}\right) 180$

(3) Interaction between two $\mathrm{CC}$ bonds when the middle carbon atom is connected to a chlorine atom $-F_{R} \mathbf{x}$<smiles>[Y]C(=C)[As]</smiles>

Environment: $\mathrm{C}_{1}-\mathrm{C}_{2}(\mathrm{X})-\mathrm{C}_{3}$; Coordinates coupled: $\left(\mathrm{C}_{1}, \mathrm{C}_{2}\right)\left(\mathrm{C}_{2}, \mathrm{C}_{3}\right)$

The other constants are defined in a similar manner.

The first 23 constants in Table 1 were transferred unaltered from the set for saturated hydrocarbons [6]; the remainder, other than $F_{\mathbf{X} \omega}$, were transferred from the set for the primary chlorides [7] ( $\omega$ corresponds to the coordinate $W$ in Fig. 2). Jacobian elements were computed for the carbon-chlorine stretching frequencies for about 25 force constants. The force constants which most influenced the splittings between the $S_{\mathrm{HH}}, S_{\mathrm{HH}}$ and $S_{\mathrm{CH}}$ frequencies were $K_{\mathrm{CX}}, F_{\mathrm{XI}}, F_{\mathrm{X} \theta}, F_{\mathrm{X} \phi}, F_{\mathrm{X} \omega}$ and $F_{R \mathrm{X}}\left(F_{\mathrm{X} \phi}\right.$ and $F_{\mathrm{X} \omega}$ are zero for primary chlorides). It was found that $F_{\mathrm{X} \omega}$ and $F_{\mathrm{X} \phi}$ were most effective in this regard, $F_{\mathrm{X} \omega}$ being much more influential than $F_{\mathbf{X} \phi}$. Since using the latter to fit the carbon-chlorine stretching frequencies was found to mar somewhat the agreement at higher frequencies, it was decided to leave this constant at zero and use only $F_{\mathbf{X}_{\omega}}$. The optimum value of -0.220 found for $F_{\mathbf{X}_{\omega}}$ necessitated slight modifications in $K_{\mathrm{X}}$ (raising it by 0.2 ) and in $K_{R}{ }^{X}$ (raising it by 0.3 ). The constant $H_{\phi}$ was decreased from its value of 0.676 in the primary chlorides in order to give agreement with the assignments of the $\mathrm{C}(\mathrm{X})-\mathrm{H}$ bending modes of 2-chloropropane, and $F_{R}{ }^{x}$ was modified from its value of 0.101 for hydrocarbons in order to obtain better agreement for the CC stretching modes of 2-chloropropane.

\section{Results for 2-chloropropane and 2-chlorobutane}

The normal coordinate calculations were done using the Wilson GF matrix method [12] and the Taylor symmetrization procedure [13], and were performed on an

[12] E. B. Wrrson, J. C. Defrus and P. C. Cross, Molecular Vibrations. MoGraw-Hill (1955).

[13] W. J. TAYLOR, J. Chem. Phys. 18, 1301 (1950). 
IBM 7090 computer. The calculation of atomic motions followed the method of HUNZIKER [14].

The 2-chloropropane molecule with its internal coordinates has been given in Fig. 2. The symmetry coordinates used in the calculations are given in Table 2. The calculated frequencies, symmetries and potential energy distributions are given in Table 3, and compared with observed liquid phase frequencies and gas phase band symmetries. Only contributions to the potential energy which are

Table 2. Symmetry coordinates for 2-chloropropane

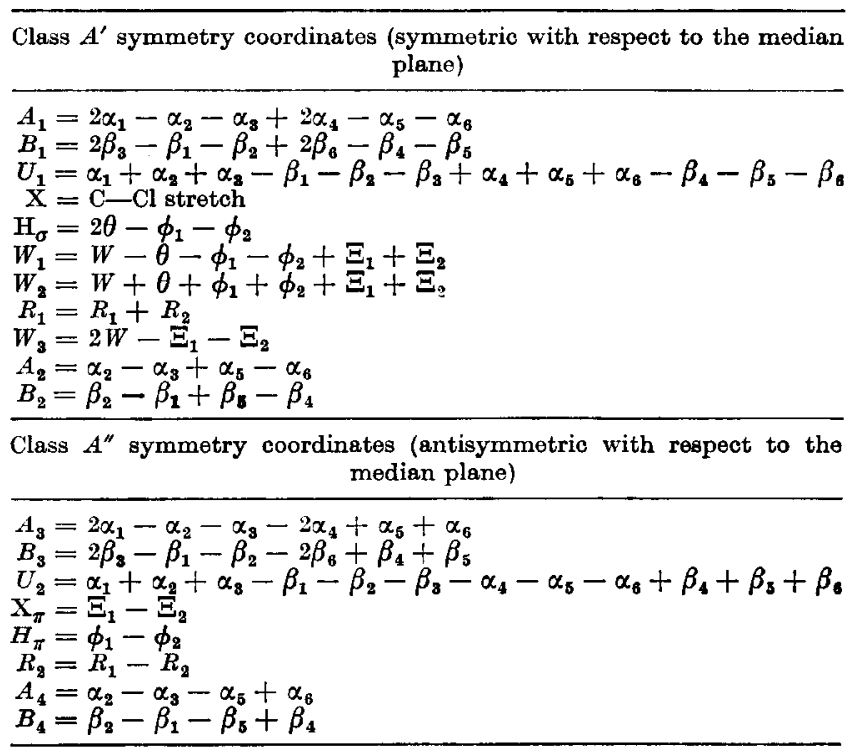

greater than 10 per cent have been included. The CH stretching frequencies, although calculated and giving good agreement, have been omitted from this and subsequent tables since they were not used in the analyses. It will be seen that the agreement between observed and calculated frequencies is reasonably good, the average deviation between observed and calculated frequencies in the range of $600-1500 \mathrm{~cm}^{-1}$ being about 0.5 per cent (frequencies below $600 \mathrm{~cm}^{-1}$ might be expected to deviate more because of the exclusion of the torsion coordinates in the calculation).

The 2-chlorobutane molecule with its internal coordinates is shown in Fig. 4. The coordinates used in the calculations are listed in Table 4 . In Table 5 are given the calculated frequencies and potential energy distributions for the three conformations of this molecule. A detailed comparison of observed and calculated frequencies is difficult because of the presence of the three isomers in the liquid. However, it can be readily seen that the carbon-chlorine stretching frequencies are satisfactorily accounted for in the three structures by our force field. A possible correlation with observed bands may be feasible by examining the effect of decreasing temperature on the spectrum, since this would be expected to favor the concentration

[14] H. Hunziker, Spectrochim. Acta 17, 131 (1961). 
Table 3. Observed and calculated frequencies and assignments for 2-chloropropane

\begin{tabular}{|c|c|c|c|c|}
\hline \multicolumn{2}{|c|}{ Observed } & \multicolumn{3}{|c|}{ Calculated } \\
\hline Frequency * & Symmetry $†$ & Frequency & Symmetry & $\begin{array}{l}\text { Potential energy } \\
\text { distribution } \ddagger\end{array}$ \\
\hline $324 \mathrm{w}$ & $\boldsymbol{A}$ & 310 & $A^{\prime \prime}$ & $\mathbf{X}_{\pi}(89)$ \\
\hline $335 \mathrm{~m}$ & $S$ & 329 & $A^{\prime}$ & $W_{3}(66)-W_{1}(16)$ \\
\hline $423 \mathrm{~m}$ & $s$ & 410 & $A^{\prime}$ & $W_{1}(62)+W_{3}(15)$ \\
\hline $611 \mathrm{vs}$ & $S$ & 611 & $A^{\prime}$ & $X(76)$ \\
\hline 677 vw & & $2 \times 335=670$ & $A^{\prime}$ & \\
\hline $760 \mathrm{w}$ & & $335+423=758$ & $A^{\prime}$ & \\
\hline $885 \mathrm{~s}$ & $s$ & 884 & $A^{\prime}$ & $R_{1}(76)+B_{1}(16)$ \\
\hline $933 \mathrm{mw}$ & $A$ & 923 & $A^{\prime \prime}$ & $B_{3}(36)+B_{a}(36)+H_{\pi}(21)$ \\
\hline $945 \mathrm{vw}$ & & $335+611=946$ & $A^{\prime}$ & \\
\hline $965 ?$ & & 965 & $A^{\prime \prime}$ & $B_{3}(35)-B_{4}(33)-R_{8}(24)$ \\
\hline $1025 \mathrm{sh}$ & & $423+611=1034$ & $A^{\prime}$ & \\
\hline $1061 \mathrm{vg}$ & $S$ & 1078 & $A^{\prime}$ & $B_{2}(51)-B_{1}(14)-H_{\sigma}(13)$ \\
\hline $1129 \mathrm{~m}$ & $A$ & 1133 & $A^{\prime \prime}$ & $R_{2}(53)-B_{4}(15)+H_{\pi}(14)$ \\
\hline $1160 \mathrm{~s}$ & $S$ & 1144 & $A^{\prime}$ & $B_{1}(44)-R_{1}(23)$ \\
\hline $1223 \mathrm{vw}$ & & $2 \times 611=1222$ & $A^{\prime}$ & \\
\hline $1260 \mathrm{vs}$ & $S$ & 1260 & $A^{\prime}$ & $H_{\sigma}(80)+B_{2}(11)$ \\
\hline $1308 \mathrm{w}$ & $S$ & $423+885=1308$ & $A^{\prime}$ & \\
\hline $1328 \mathrm{w}$ & $A$ & 1323 & $A^{\prime \prime}$ & $H_{\pi}(55)-R_{2}(17)$ \\
\hline $1374 \mathrm{~s}$ & $\boldsymbol{A}$ & 1375 & $A^{\prime \prime}$ & $U_{2}(84)$ \\
\hline $1385 \mathrm{~s}$ & $s$ & 1378 & $A^{\prime}$ & $U_{1}(95)$ \\
\hline & & $(1462$ & $A^{\prime \prime}$ & $A_{4}(86)$ \\
\hline $1446 \mathrm{~s})$ & & 1464 & $A^{\prime}$ & $A_{1}(83)$ \\
\hline $1465 \mathrm{~g}\}$ & & 1467 & $A^{\prime}$ & $A_{2}(81)$ \\
\hline & & $(1467$ & $A^{\prime \prime}$ & $A_{3}(82)$ \\
\hline
\end{tabular}

* Liquid phese frequencies.

$\dagger$ From gas phase band contours. nates.

$\ddagger$ In per cent with only coordinates contributing $>10$ per cent included. See Table 2 for definition of coordi-

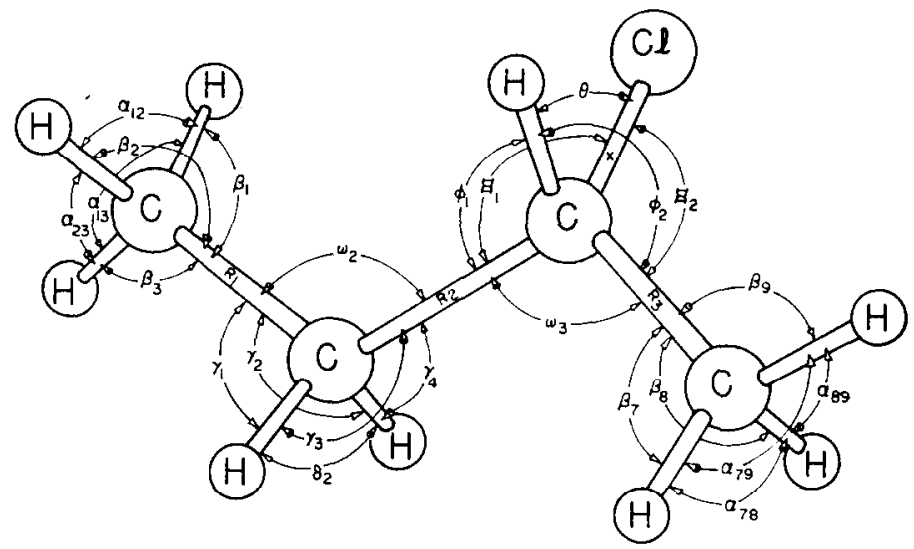

Fig. 4. Molecule of 2-chlorobutane with internal coordinates.

of one isomer. In Table 6 are listed the observed frequencies of liquid 2-chlorobutane [2], together with the effect of decreasing temperature on the relative intensities of the bands [15] (in this case after cooling for several hours with liquid nitrogen, without freezing of the sample). It will be seen that, judging from the carbonchlorinestretching frequencies, the $S_{\mathrm{HH}}$ conformation is favored at lower temperature. We have therefore tried to assign those bands which remain intense at low temperature

[15] J. J. SHIPMAN, private communication. 
Table 4. Coordinates for 2-chlorobutane

$$
\begin{aligned}
R_{1} & =R_{1} \\
R_{2} & =R_{2} \\
R_{3} & =R_{3} \\
\mathrm{X} & =\mathrm{X} \\
U_{1} & =\alpha_{12}+\alpha_{13}+\alpha_{23}-\beta_{1}-\beta_{2}-\beta_{8} \\
A_{11} & =2 \alpha_{12}-\alpha_{13}-\alpha_{23} \\
A_{2 l} & =\alpha_{18}-\alpha_{28} \\
B_{11} & =2 \beta_{1}-\beta_{2}-\beta_{8} \\
B_{2 l} & =\beta_{2}-\beta_{8} \\
\delta & =4 \delta_{2}-\gamma_{1}-\gamma_{2}-\gamma_{8}-\gamma_{4} \\
\mathrm{CCC} & =5 \omega_{2}-\delta_{2}-\gamma_{1}-\gamma_{2}-\gamma_{8}-\gamma_{4} \\
t & =\gamma_{1}-\gamma_{2}-\gamma_{3}+\gamma_{4} \\
r & =\gamma_{1}-\gamma_{2}+\gamma_{3}-\gamma_{4} \\
\omega & =\gamma_{1}+\gamma_{2}-\gamma_{8}-\gamma_{4} \\
H & =2 \theta-\phi_{1}-\phi_{2} \\
W_{1} & =\omega_{8}-\theta-\phi_{1}-\phi_{2}+\Xi_{1}+\Xi_{2} \\
W_{2} & =2 \omega_{9}-\Xi_{1}-\Xi_{3} \\
\mathrm{X}_{\pi} & =\Xi_{1}-\Xi_{2} \\
H_{\pi} & =\phi_{1}-\phi_{2} \\
U_{r} & =\alpha_{78}+\alpha_{79}+\alpha_{89}-\beta_{7}-\beta_{8}-\beta_{9} \\
A_{1 r} & =2 \alpha_{78}-\alpha_{99}-\alpha_{89} \\
A_{2 r} & =\alpha_{29}-\alpha_{89} \\
B_{1 r} & =2 \beta_{7}-\beta_{8}-\beta_{9} \\
B_{3 r} & =\beta_{8}-\beta_{9}
\end{aligned}
$$

\begin{tabular}{|c|c|}
\hline $\begin{array}{l}\text { Frequency } \\
\left(\mathrm{cm}^{-1}\right)\end{array}$ & Potential energy distribution \\
\hline 213 & $\mathrm{X}_{\pi}(37)+\operatorname{CCC}(28)-W_{8}(23)$ \\
\hline 313 & $W_{3}(55)+X_{n}(23)$ \\
\hline 376 & $W_{1}(59)-\operatorname{CCC}(12)$ \\
\hline 454 & $\operatorname{CCC}(36)+W_{1}(12)$ \\
\hline 611 & $\mathrm{X}(75)$ \\
\hline 776 & $r(44)+B_{12}(18)-B_{22}(14)$ \\
\hline 843 & $R_{2}(32)-B_{2 \tau}(18)$ \\
\hline 956 & $B_{2 r}(24)-B_{1 l}(20)+H_{\pi}(18)$ \\
\hline 1004 & $B_{1 r}(35)-B_{2 l}(16)+R_{3}(15)$ \\
\hline 1022 & $R_{1}(63)-R_{8}(15)$ \\
\hline 1089 & $B_{2 l}(27)+r(14)$ \\
\hline 1109 & $R_{g}(43)-B_{1 \mathrm{r}}(12)$ \\
\hline 1155 & $R_{2}(31)+B_{2 r}(13)$ \\
\hline 1232 & $H_{\sigma}(43)+t(21)-B_{12}(14)$ \\
\hline 1263 & $H_{\pi}(33)+\omega(25)+H_{\sigma(13)}$ \\
\hline 1291 & $t(48)-H_{\sigma}(26)$ \\
\hline 1362 & $U_{2}(65)-B_{\pi}(11)$ \\
\hline 1373 & $U_{r}(87)$ \\
\hline 1390 & $\omega(30)-U_{l}(25)-H_{\pi}(11)$ \\
\hline 1450 & $\delta(90)$ \\
\hline 1460 & $A_{2 r}(42)-A_{1 r}(23)+A_{11}(22)$ \\
\hline 1460 & $A_{22}(91)$ \\
\hline 1461 & $A_{9 r}(44)+A_{1 r}(38)$ \\
\hline 1465 & $A_{12}(62)+A_{15}(25)$ \\
\hline
\end{tabular}

Table 5. Caloulated frequencies and potential energy distributions for 2-chlorobutane

(a) $S_{\text {HE }}$ conformation 
Table 5 (cont.)

(b) $S_{\mathrm{HH}^{\prime}}$ conformation

\begin{tabular}{|c|c|}
\hline $\begin{array}{l}\text { Frequenoy } \\
\left(\mathrm{cm}^{-1}\right)\end{array}$ & Potential energy distribution \\
\hline 208 & $\operatorname{ccC}(37)+W_{1}(34)+\mathbf{X}_{\pi}(15)$ \\
\hline $\mathbf{3 1 7}$ & $\mathrm{X}_{\pi}(\mathbf{5 8})-W_{1}(15)$ \\
\hline 328 & $W_{2}(75)$ \\
\hline 540 & $\operatorname{CCC}(27)-X(26)-W_{1}(21)$ \\
\hline 631 & $\mathrm{X}(59)$ \\
\hline 779 & $r(46)+B_{1 l}(29)$ \\
\hline $\begin{array}{l}840 \\
946\end{array}$ & $\begin{array}{l}R_{2}(44)+R_{1}(18)+R_{3}(11)-B_{9 r}(11) \\
R,(28)-R_{2}(22)+B_{9}(17)+H_{-}(11)\end{array}$ \\
\hline 993 & $B_{2 l}(19)+B_{2 r}(19)+R_{3}(17)$ \\
\hline 1009 & $B_{1 r}(37)+\omega(16)-B_{2 l}(13)-B_{1 l}(11)$ \\
\hline 1084 & $B_{13}(22)+R_{1}(16)$ \\
\hline 1121 & $R_{15}(15)+R_{9}(13)-R_{1}(13)$ \\
\hline 1147 & $R_{\mathrm{g}}(30)-r(13)$ \\
\hline 1231 & $H_{\sigma}(69)$ \\
\hline 1264 & $t(54)$ \\
\hline 1320 & $\dot{H}_{\pi}(50)+t(11)$ \\
\hline 1332 & $\omega(41)+U_{3}(24)+R_{3}(12)$ \\
\hline 1372 & $U_{n}(83)$ \\
\hline 1380 & $U_{2}(62)-\omega(15)$ \\
\hline 1452 & $\delta(\mathbf{8 4})$ \\
\hline 1460 & $A_{2 r}(73)+A_{12}(14)$ \\
\hline 1460 & $A_{\mathrm{g} b}(91)$ \\
\hline 1462 & $A_{1 r}(66)+\delta(11)$ \\
\hline 1464 & $A_{1 l}(62)+A_{1 r}(13)$ \\
\hline
\end{tabular}

(c) $S_{\text {CH }}$ conformation

\begin{tabular}{|c|c|}
\hline $\begin{array}{c}\text { Frequenoy } \\
\left(\mathrm{om}^{-1}\right)\end{array}$ & Potential energy distribution \\
\hline 218 & $W_{2}(40)+\operatorname{cCC}(26)$ \\
\hline 295 & $\mathbf{X}_{\pi}(70)$ \\
\hline 390 & $W_{1}(54)+\operatorname{CCC}(14)$ \\
\hline 418 & $W_{8}(27)+W_{1}(24)-\operatorname{ccc}(18)$ \\
\hline 676 & $\mathbf{X}(\mathbf{6 2})$ \\
\hline 762 & $r(53)+B_{12}(27)$ \\
\hline 857 & $R_{2}(35)-B_{21}(17)-B_{2 r}(16)+R_{3}(13)$ \\
\hline 951 & $B_{2 l}(23)-B_{2 r}(21)-B_{\pi}(14)$ \\
\hline 975 & $R_{9}(25)+B_{12}(22)+t(19)$ \\
\hline 1021 & $R_{1}(51)+B_{1 r}(25)$ \\
\hline 1073 & $B_{1 r}(30)-R_{1}(17)-B_{21}(13)$ \\
\hline 1138 & $R_{8}(28)-B_{1 l}(13)$ \\
\hline 1155 & $R_{2}(29)$ \\
\hline 1235 & $H_{\sigma}(30)-t(20)-H_{\pi}(11)$ \\
\hline 1267 & $H_{a}(48)+t(21)$ \\
\hline 1296 & $\omega(42)-t(18)$ \\
\hline 1351 & $U_{l}(27)-H_{\pi}(23)+U_{r}(12)$ \\
\hline 1373 & $U_{r}(76)-U_{z}(13)$ \\
\hline 1383 & $U_{2}(46)-\omega(16)$ \\
\hline 1451 & $\delta(\mathbf{8 8})$ \\
\hline 1460 & $A_{1 r}(39)+A_{2 r}(32)-A_{1 l}(18)$ \\
\hline 1460 & $A_{3 b}(80)$ \\
\hline 1461 & $A_{9 r}(55)-A_{1 r}(17)$ \\
\hline 1464 & $A_{1 l}(54)+A_{1 r}(30)$ \\
\hline
\end{tabular}


to the $S_{\mathrm{HH}}$ conformation, and to determine if the remaining bands can be assigned reasonably to vibrations of the $S_{\mathrm{HH}}$, and $S_{\mathrm{CH}}$ structures. Study of Table 6 indicates that this is quite satisfactorily achieved. Using the assignments for the $S_{\mathrm{HH}}$ conformation, the average deviation between observed and calculated frequencies in the range of $600-1500 \mathrm{~cm}^{-1}$ is found to be about 0.5 per cent.

Table 6. Assignments to observed frequencies of 2-chlorobutane

\begin{tabular}{|c|c|c|c|}
\hline \multirow{2}{*}{$\begin{array}{l}\text { Observed liquid } \\
\text { frequenoy } \\
\left(\mathrm{cm}^{-1}\right)\end{array}$} & \multicolumn{3}{|c|}{ Calculated frequency } \\
\hline & $S_{\text {HH }}$ & $S_{\mathrm{HB}}$ & $S_{\text {OH }}$ \\
\hline$\sim 290 \mathrm{w}$ & & & 295 \\
\hline $324 \mathrm{~m}$ & 313 & 317 & \\
\hline $333 \mathrm{sh}$ & & 328 & \\
\hline $374 \mathrm{mt}$ & & & 390 \\
\hline $386 \mathrm{~m} *$ & 376 & & \\
\hline $418 \mathrm{mw} \dagger$ & & & 418 \\
\hline $460 \mathrm{mw}^{*}$ & 454 & & \\
\hline $522 \mathrm{m \dagger}$ & & 540 & \\
\hline $607 \mathrm{vs}^{*}$ & 811 & & \\
\hline $627 \mathrm{~m} \dagger$ & & 631 & \\
\hline $670 \mathrm{st}$ & & & 676 \\
\hline 790 v8* & 776 & 779 & 762 \\
\hline $822 \mathrm{~m} \dagger$ & & 840 & \\
\hline $843 \mathrm{~g}^{*}$ & 843 & & 857 \\
\hline $950 \mathrm{~ms}+$ & & 946 & 951 \\
\hline $958 \mathrm{~ms}^{*}$ & 956 & & \\
\hline $976 \mathrm{w} \dagger$ & & & 975 \\
\hline $992 \mathrm{~m}^{*}$ & 1004 & & \\
\hline$\sim 1000(?) \dagger$ & & 993 & \\
\hline $1010 w \dagger$ & & 1009 & \\
\hline $1022 w^{*}$ & 1022 & & 1021 \\
\hline $1060 \mathrm{~m}+$ & & 1084 & 1073 \\
\hline $1073 \mathrm{mw}^{*}$ & 1089 & & \\
\hline $1108 \mathrm{w} *$ & 1109 & & \\
\hline $1118 \mathrm{~m}+$ & & 1121 & \\
\hline 1140 vw & & & 1138 \\
\hline 1157 a & 1155 & 1147 & 1155 \\
\hline 1238 v8 & 1232 & 1231 & 1235 \\
\hline $1265 \mathrm{vw}$ & & 1264 & \\
\hline $1286 \mathrm{s \ddagger}$ & 1263 & & 1267 \\
\hline 1297 d & 1291 & & 1296 \\
\hline $1320 \mathrm{mw} \dagger$ & & 1320 & \\
\hline $1347 \mathrm{vw}$ & & 1332 & 1351 \\
\hline $1360 \mathrm{w} *$ & 1362 & 1372 & 1373 \\
\hline $1382 \mathrm{vg} \ddagger$ & $\begin{array}{l}1373 \\
1390\end{array}$ & 1380 & 1383 \\
\hline 1447 vB & 1450 & 1452 & 1451 \\
\hline & 1460 & 1460 & 1460 \\
\hline 1460 v8 & 1460 & 1460 & 1460 \\
\hline & 1461 & 1462 & 1461 \\
\hline & 1465 & 1464 & 1464 \\
\hline
\end{tabular}

* Relative intensity increases on cooling.

† Relative intensity decreases on cooling.

$\ddagger$ Remains gtrong at low temperature.

\section{Tests of the Force Field}

The results on 2-chloropropane and 2-chlorobutane encouraged us to think that a satisfactory force field had been derived for secondary chlorides. In order to evaluate this conclusion we applied the force field to the calculation of the frequencies of other chlorinated hydrocarbons, containing either a single chlorine atom or two 
chlorine atoms in a 2,4 position. Particular attention was given to molecules whose conformation was unambiguous, and to the ability of the force field to predict the carbon-chlorine stretching frequencies.

\section{Monochlorohydrocarbons}

Application of the force field to linear monochlorohydrocarbons of known structure gave satisfactory results. Thus, for the $S_{\mathrm{HH}}$ conformation of 3-chloropentane, whose spectrum can be identified since only this isomer is present in the solid state [5], the calculated carbon-chlorine stretching frequency was $610 \mathrm{~cm}^{-1}$ while the observed band is found at $606 \mathrm{~cm}^{-1}$ [5]. Good agreement is also obtained for the other modes of this molecule. (Detailed assignments for 3-chloropentane will be discussed in a subsequent paper.)

In order to examine the predictive ability of the force field for conformations other than those from which it was derived, the normal modes of the two conformational isomers of monochlorocyclohexane were calculated. In the axial form of this molecule the chlorine conformation is $S_{\mathrm{H}^{\prime} \mathrm{H}}$, whereas in the equatorial form the conformation is $S_{\mathrm{CC}}$. Experimental studies of the spectrum of this molecule [4] permit the isolation of the equatorial form in the solid state and, by difference from the liquid state spectrum, the identification of some of the bands of the axial form. A comparison between observed and calculated frequencies is given in Table 7 , which incorporates the above information as well as some intensity and Raman polarization data in order to make assignments. It will be seen that, other than in the $1300-1500 \mathrm{~cm}^{-1}$ region where much overlap occurs and detailed comparisons are therefore difficult, the observed bands are well accounted for. This is not only true for the carbon-chlorine stretching vibrations, but selective agreement is evident elsewhere in the spectrum. For the suggested assignments the average deviation in the range of $500-1300 \mathrm{~cm}^{-1}$ is about 0.8 per cent for both conformations. We might note incidentally that although the carbon-chlorine stretching mode of the axial form was assigned to the band at $683 \mathrm{~cm}^{-1}[4]$, the $557 \mathrm{~cm}^{-1}$ band is more justifiably given this designation on the basis of the potential energy distributions in these modes. The larger intensity of the latter band supports this conclusion.

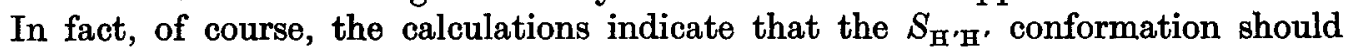
really be considered to have two characteristic "carbon-chlorine stretching frequencies" associated with it, in distinction to the single frequencies associated with the other conformations.

\section{2,4-dichlorohydrocarbons}

The force field was also applied to hydrocarbons with chlorine atoms in a 2,4 position, i.e., separated by a $\mathrm{CH}_{2}$ group. The aim here was to see if the interactions which lead to frequency splittings would be satisfactorily reproduced. The molecules chosen for this test were the $d l$ and meso 2,4-dichloropentanes, since the liquid form of each contains essentially one stable conformation $[15,16]$.

The $d l$ form of 2,4-dichloropentane is shown in Fig. 5, with its internal coordinates. This is the most stable conformation in tho liquid [16]. It is designated $T T$, for the trans arrangement of carbon-carbon bonds across both $R 2$ and $R 3$. The symmetry coordinates for this structure, which has $C_{2}$ symmetry, are given in Table 8 .

[16] T. Shimanodoni and M. Tasum, Spectrochim. Acta 17, 755 (1961). 
Table 7. Observed and calculated frequencies of monochlorocyclohexane, with potential energy distributions and possible assignments

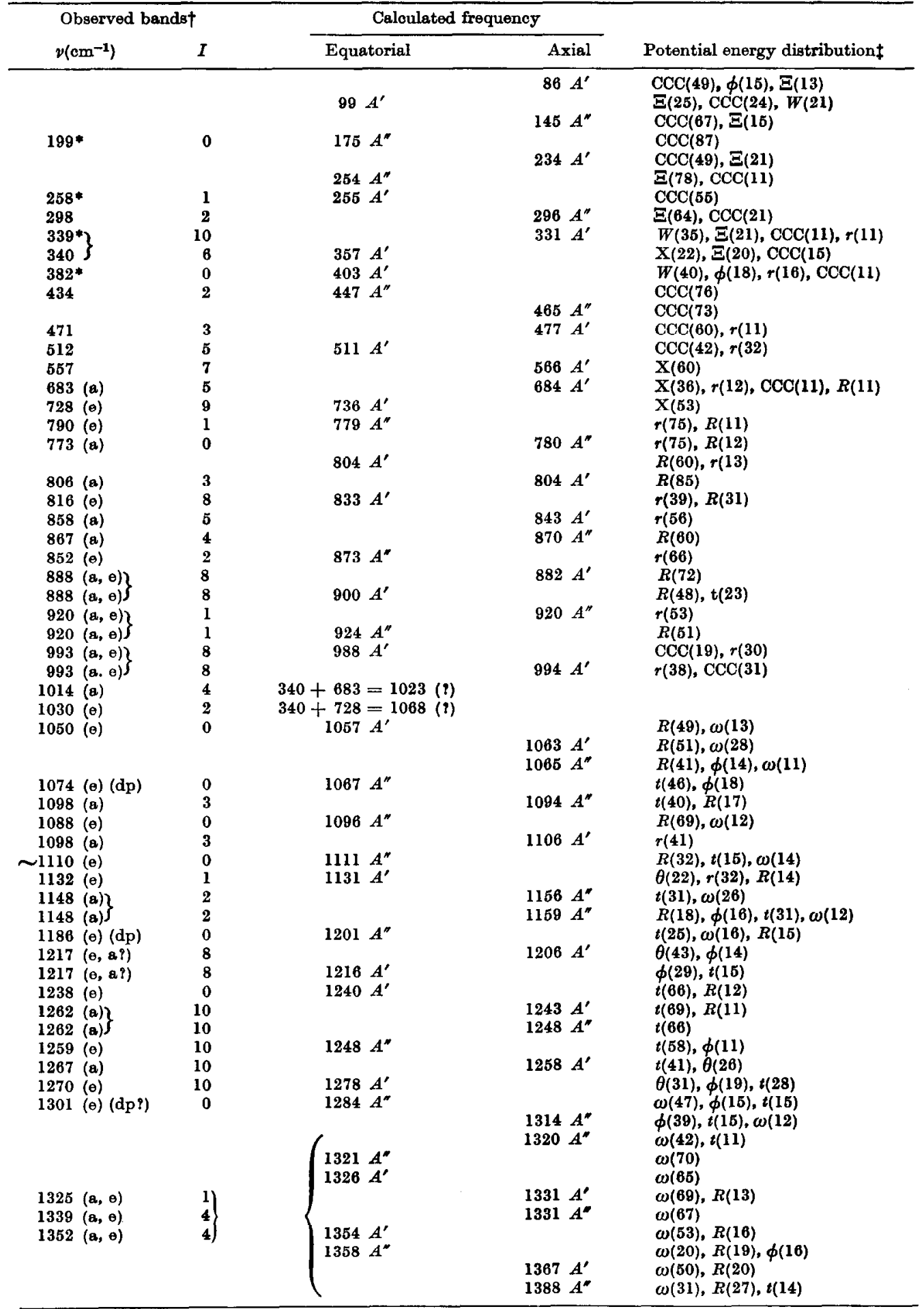


Table 7 (cont.)

\begin{tabular}{|c|c|c|c|c|}
\hline \multirow{2}{*}{\multicolumn{2}{|c|}{$\begin{array}{l}\text { Observed bands } \\
\nu\left(\mathrm{cm}^{-1}\right)\end{array}$}} & \multicolumn{2}{|c|}{ Caloulated frequency } & \multirow[b]{2}{*}{ Potential energy distribution } \\
\hline & & Equetorial & Axial & \\
\hline $\begin{array}{l}1434(a, e) \\
1450(a, e) \\
1462(a, e)\end{array}$ & $\left.\begin{array}{r}1 \\
10 \\
1\end{array}\right)$ & $\left\{\begin{array}{l}1400 A^{\prime \prime} \\
1450 A^{\prime} \\
1452 A^{\prime \prime} \\
1453 A^{\prime} \\
1454 A^{\prime \prime} \\
1458 A^{\prime}\end{array}\right.$ & $\begin{array}{l}1451 A^{\prime} \\
1453 A^{\prime \prime} \\
1454 A^{\prime} \\
1455 A^{\prime \prime} \\
1450 A^{\prime}\end{array}$ & $\begin{array}{l}R(23), \phi(12), \omega(11), t(11) \\
\delta(97) \\
\delta(97) \\
\delta(98) \\
\delta(97) \\
\delta(92) \\
\delta(91) \\
\delta(98) \\
\delta(92) \\
\delta(97) \\
\delta(97)\end{array}$ \\
\hline
\end{tabular}

* Raman band.

+ Liquid phase frequencies from Ref. [4] ( $I=$ intensity).

¥ Coordinates have general physical oharacter similar to those of 2-chlorobutane (see Fig. 4 and Table 4).

(a) = Band present only in axial isomer.

(e) = Band present in equatorial isomer (solid state spectrum).

$(a, \theta)=$ Bands common to both isomers.

dp $=$ Depolarized Raman band.

Table 8. Symmetry coordinates for $d l$ 2,4-dichloropentane

Clags $A$ coordinates

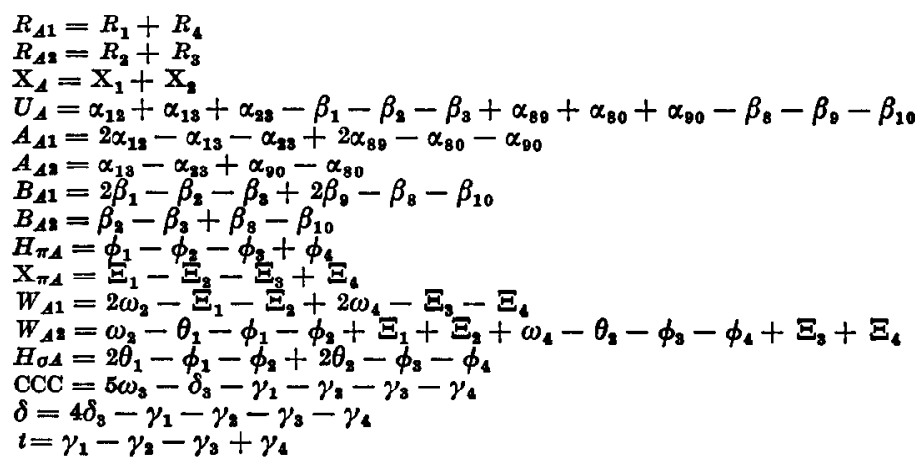

Class $B$ coordinates

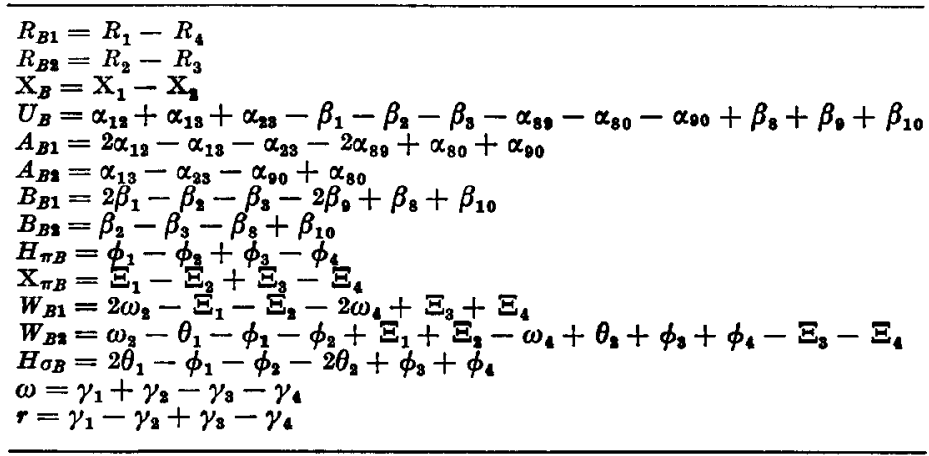




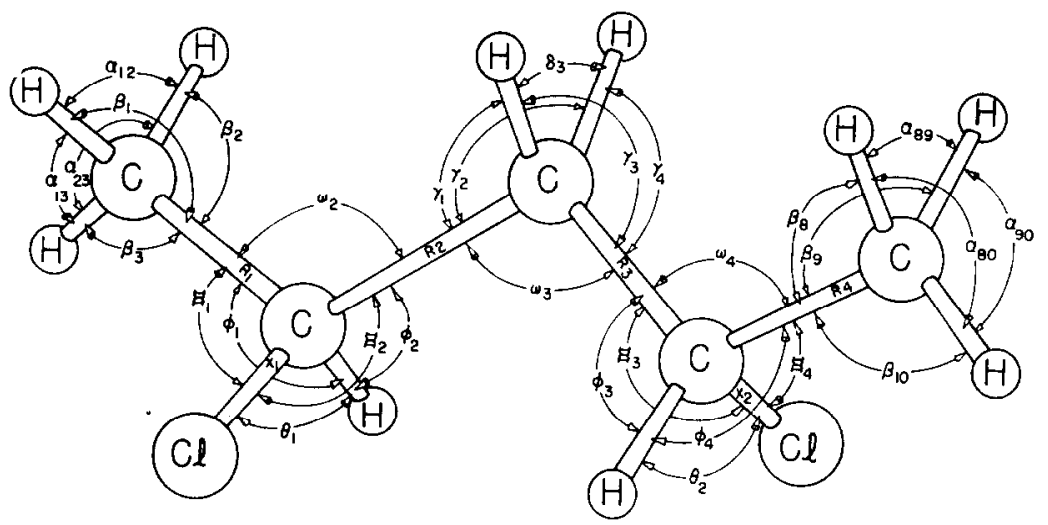

Fig. 5. Molecule of $d l$ 2,4-dichloropentane ( $T T$ conformation) with internal coordinates.

Table 9. Observed and calculated frequencies and potential energy distributions of $T T$ conformation of $d l$ 2,4-dichloropentane

\begin{tabular}{|c|c|c|}
\hline \multirow[b]{2}{*}{$\begin{array}{l}\text { Observed frequency } \\
\qquad\left(\mathrm{cm}^{-1}\right)\end{array}$} & \multicolumn{2}{|r|}{ Calculated } \\
\hline & Frequency $\left(\mathrm{cm}^{-1}\right)$ & Potential energy distribution \\
\hline \multirow{3}{*}{255 vw } & $122 A$ & $\mathrm{CCC}(39)-\mathrm{X}_{\pi_{\Delta}}(32)-\mathrm{W}_{\Delta 1}(21)$ \\
\hline & $266 A$ & $W_{A I}(51)-X_{\pi_{A}}(30)$ \\
\hline & $283 B$ & $\mathrm{X}_{\pi_{B}}(39)+W_{B 1}(37)$ \\
\hline $343 \mathrm{~m}$ & $325 B$ & $W_{B 1}(35)-\mathrm{X}_{\pi B}(30)-W_{B 2}(17)$ \\
\hline \multirow[t]{2}{*}{$368 \mathrm{~m}$} & $354 \mathrm{~A}$ & $W_{A 2}(67)-W_{A 1}(14)$ \\
\hline & $446 B$ & $W_{B 2}(55)+W_{B 1}(16)$ \\
\hline $460 \mathrm{mw}$ & $466 A$ & $\mathrm{CCC}(30)+\mathrm{X}_{\pi A}(26)+R_{A 1}(18)$ \\
\hline $606 \mathrm{~s}$ & $605 B$ & $\mathrm{X}_{B}(78)$ \\
\hline $627 \mathrm{~s}$ & $624 A$ & $\mathrm{X}_{A}(\mathbf{7 4})$ \\
\hline $877 \mathrm{~ms}$ & $\begin{cases}872 & A \\
877 & B\end{cases}$ & $\begin{array}{l}R_{A 2}(33)-B_{A 1}(27)-B_{A 2}(11) \\
r(48)-B_{B 1}(22)+H_{\pi B}(16)\end{array}$ \\
\hline $938 \mathrm{~s}$ & $943 B$ & $R_{B 1}(32)+R_{B 2}(26)-B_{B 1}(19)$ \\
\hline $978 \mathrm{~m}$ & $994 A$ & $B_{A 2}(31)-B_{A 1}(20)+R_{A 1}(13)+H_{\pi A}(11)$ \\
\hline 1012 B & $1017 B$ & $B_{B 2}(45)+R_{B 1}(32)$ \\
\hline $1067 \mathrm{~m}$ & $1086 B$ & $B_{B 1}(27)+R_{B 1}(23)+H_{\sigma_{B}}(14)$ \\
\hline $1100 \mathrm{vw}$ & $1110 A$ & $R_{A 1}(47)+B_{A 1}(18)$ \\
\hline $1125 \mathrm{~s}$ & $1121 A$ & $B_{A 2}(27)+R_{A 2}(26)-H_{\pi_{A}}(13)$ \\
\hline $1132 \mathrm{~s} ?$ & $1145 B$ & $R_{B 2}(44)+B_{B 2}(14)-H_{\pi B}(14)$ \\
\hline $1191 \mathrm{~m}$ & $1176 A$ & $H_{\sigma_{A}}(43)+t(35)$ \\
\hline $1222 \mathrm{vw}$ & $1239 B$ & $H_{\pi_{B}}(38)-\omega(38)$ \\
\hline $1257 \mathrm{~s}$ & $1255 B$ & $H_{\sigma_{B}}(81)$ \\
\hline $1288 \mathrm{~s}$ & $1285 A$ & $H_{\sigma_{A}}(43)-t(22)-H_{\pi_{A}}(12)$ \\
\hline $1325 \mathrm{mw}$ & $1327 A$ & $H_{\pi A(49)}-t(19)$ \\
\hline $1379 \mathrm{~s}$ & $\begin{cases}1373 B \\
107\end{cases}$ & $U_{B}(92)$ \\
\hline $1578 \mathrm{~s}$ & $\{1374 \mathrm{~A}$ & $U_{\Delta}(86)$ \\
\hline $1415 \mathrm{~ms}$ & $1405 B$ & $\omega(36)-R_{B 2}(26)-H_{\pi B}(22)$ \\
\hline & $(1452 A$ & $\delta(95)$ \\
\hline $1443 \mathrm{~g})$ & $1461 A$ & $A_{A 8}(84)$ \\
\hline $\left.\begin{array}{l}14408 \\
1450 \mathrm{~m}\end{array}\right\}$ & $1461 A$ & $A_{A 1}(83)$ \\
\hline & $1461 B$ & $A_{B 2}(84)$ \\
\hline & $1464 B$ & $A_{B 1}(78)$ \\
\hline
\end{tabular}


The TT conformation of meso 2,4-dichloropentane has $C_{s}$ symmetry, so that the coordinates of Table 8 can be used in this case with the $A^{\prime}$ coordinates corresponding to the $A$ and the $A^{\prime \prime}$ coordinates to the $B$, except that the $r$ and $t$ coordinates exchange places. The stable conformation of meso 2,4-dichloropentane is the $T G$ form [16] $(G=$ gauche $)$, and our calculations were done for this structure.

The comparisons between observed $[15,16]$ and calculated frequencies for these

Table 10. Observed and calculated frequencies and potential energy distributions of $T G$ conformation of meso 2,4-dichloropontane

\begin{tabular}{|c|c|c|}
\hline \multirow[b]{2}{*}{$\begin{array}{l}\text { Observed frequency } \\
\qquad\left(\mathrm{cm}^{-1}\right)\end{array}$} & \multicolumn{2}{|r|}{ Calculated } \\
\hline & $\begin{array}{l}\text { Frequency } \\
\left(\mathrm{cm}^{-1}\right)\end{array}$ & Potential energy distribution \\
\hline & 125 & $\mathrm{CCC}(33)-W_{B 1}(31)-\mathrm{x}_{\pi_{B}}(11)$ \\
\hline & 223 & $\mathrm{X}_{\pi \Delta}(70)-R_{A_{2}}(12)$ \\
\hline $315 \mathrm{w}$ & 305 & $W_{\Delta 1}(64)+X_{\pi B}(11)$ \\
\hline $345 \mathrm{~m}$ & 325 & $\mathrm{X}_{\pi B(33)}-W_{B 1}(26)+W_{B 2}(14)$ \\
\hline $392 \mathrm{w}$ & 385 & $W_{A 2}(58)+\ddot{X}_{\pi_{A}(11)}$ \\
\hline $410 \mathrm{~ms}$ & 419 & $W_{B 2}(29)-\mathrm{x}_{\pi_{B}}(16)-\operatorname{CCC}(12)$ \\
\hline $460 \mathrm{w}$ & 449 & $W_{B 2}(35)+W_{B 1}(\mathbf{1 5})$ \\
\hline $611 \mathrm{vs}$ & 614 & $\mathrm{X}_{A}(52)+\mathrm{X}_{B}(\mathbf{2 3})$ \\
\hline $680 \mathrm{vs}$ & 675 & $\mathrm{X}_{B}(40)-\mathrm{X}_{A}(21)$ \\
\hline 855 s & 855 & $r(48)+H_{\pi B}(11)$ \\
\hline $882 \mathrm{~m}$ & 889 & $B_{\Delta 1}(27)-R_{A 2}(24)$ \\
\hline $926 \mathrm{~s}$ & 922 & $B_{B 1}(28)-R_{B 1}(23)-R_{B 2}(21)$ \\
\hline $980 \mathrm{~ms}$ & 999 & $B_{B 2}(20)-B_{A 1}(16)+R_{B 1}(12)+B_{A 2}(12)$ \\
\hline $1006 \mathrm{~s}$ & 1023 & $B_{A 3}(29)+R_{A 1}(26)-B_{B 2}(14)$ \\
\hline $1058 \mathrm{~s}$ & 1070 & $R_{A 1}(19)+B_{B 2}(15)+B_{A 1}(13)$ \\
\hline $1089 \mathrm{mw}$ & 1104 & $R_{B 1}(24)+B_{B 1}(15)$ \\
\hline $1130 \mathrm{vg}$ & $\{137$ & $R_{A 2}(28)+B_{A 2}(11)+R_{B 1}(11)$ \\
\hline $1130 \mathrm{vs}$ & 21147 & $R_{R 2}(39)+B_{B 2}(16)-H_{\pi_{B}}(13)$ \\
\hline $1199 \mathrm{~m}$ & 1186 & $H_{\sigma_{\Delta}}(34)+t(33)$ \\
\hline $1237 \mathrm{~s}$ & 1232 & $H_{\sigma_{B}}(30)+\omega(27)+H_{\pi_{B}}(13)$ \\
\hline $1272 \mathrm{~s}$ & 1265 & $H_{\sigma_{B}}(51)-\omega(14)$ \\
\hline $1289 \mathrm{~m}$ & 1276 & $H_{\sigma_{A}}(\mathbf{4 9})$ \\
\hline $1337 \mathrm{mw}$ & 1332 & $H_{\pi_{A}}(41)-t(27)$ \\
\hline $1378 \mathrm{yg}$ & $\{1372$ & $U_{B}(\mathbf{8 4})$ \\
\hline $1378 \mathrm{vs}$ & $\{1374$ & $U_{A}(\mathbf{7 7})$ \\
\hline 1416 vw & $\begin{array}{r}1390 \\
1451\end{array}$ & $\begin{array}{l}\omega(28)-H_{\pi B}(27)-R_{B 2}(24) \\
\delta(91)\end{array}$ \\
\hline $1427 \mathrm{w})$ & 1461 & $A_{B 2}(75)$ \\
\hline 1439 s & 1461 & $A_{12}(88)$ \\
\hline $1453 \mathrm{~s}$ & 1462 & $A_{A 1}(79)$ \\
\hline & 1463 & $A_{B 1}(78)$ \\
\hline
\end{tabular}

two structures are given in Tables 9 and 10. For the assignments proposed in these tables the average deviation between observed and calculated frequencies in the range of $600-1400 \mathrm{~cm}^{-1}$ is about 0.6 per cent for the $d l$ compound and about 0.8 per cent for the meso compound. $\Lambda \mathrm{s}$ will be seen, the carbon-chlorine frequencies are predicted quite well.

It may be worth remarking on the interaction splittings of the carbon-chlorine stretching frequencies in the two isomers of the 2,4-dichloropentanes. This splitting may seem large in view of the separation of the two $\mathrm{CHCl}$ groups by the intervening $\mathrm{CH}_{2}$ group. However, we must recognize that the so-called carbon-chlorine stretching mode is far from a pure "group frequency". We have calculated the atomic motions corresponding to this mode in the three conformations of 2-chlorobutane, and these are shown schematically in Fig. 6. It will be seen from these figures that the carbon 
atom attached to the chlorine and the two carbon atoms on either side of this carbon atom all partake significantly in the motion during this vibration. We should really designate the four-atom group $\mathrm{C}-\mathrm{C}(\mathrm{Cl})-\mathrm{C}$ as the "group" involved in this frequency. It should therefore not be surprising that when two such "groups" are joined together, as they are in 2,4-dichloropentane, the characteristic frequency is significantly affected by their mechanical coupling. Furthermore, this coupling
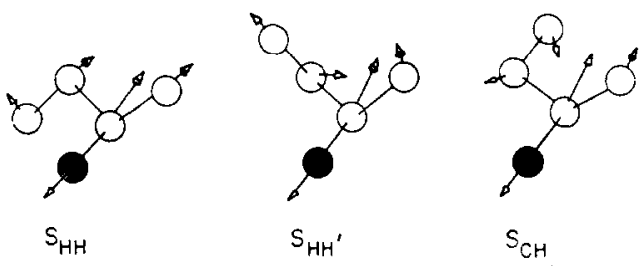

Fig. 6. Atomic motions of chlorine and carbon atoms in the carbon-chlorine stretching vibration of the three conformations of 2-chlorobutane.

will be a function of geometry (i.e., conformation) since the detailed atomic motions reflect the location of the next-nearest-neighbor carbon atoms (see Fig. 6).

\section{Conchustons}

We have developed a force field for secondary chlorides based on the extension of existing force fields for hydrocarbons and primary chlorides and based on the premise that the empirically observed conformation dependence of the carbonchlorine stretching frequencies arises predominantly through changes in the $G$ matrix. The results of testing this force field on several independent molecules lead us to believe that the latter assumption is a valid one. We of course recognize that this force field may not be the last word on the subject: Questions of uniqueness always exist, torsion coordinates must be included, and refinement to tetrahedral geometry may present problems [17]. However, the generally good agreement between observed and calculated frequencies for the molecules considered indicates to us that the proposed force field is a good one, that eventual refinement will probably be minor, and that it is presently useful and reliable in investigating conformational questions involving secondary chlorides not containing 1,2-dichloro structures. We have applied it successfully to the analysis of the spectrum of poly(vinyl chloride), which will be reported on later.

Acknowledgments-We are indebted to R. G. SNYDER and J. H. Schachischnerder of the Shell Development Co., Emeryville, California, for permitting us to use their force field for primary chlorides prior to publication. We are deeply gruteful to J. J. SHupman of the B. F. Goopricr Co., Brecksville, Ohio, for the spectral data on 2-chloropropane and 2-chlorobutane, and for the low frequency bands of the 2,4-dichloropentanes. This research was supported by a grant from the National Seience Foundation.

[17] C. G. Opaskar and S. Krimm, Spectrochim. Acta 21, 1165 (1965). 